\title{
Diversity Management Practices in the US Tech Companies
}

\author{
Emil VELINOV ${ }^{1,2}$ \\ ${ }^{1}$ Skoda Auto University, Mlada Boleslav, Czech Republic \\ emil.velinovesavs.cz \\ ${ }^{2}$ RISEBA University of Business, Arts and Technology, Riga, Latvia \\ emil.velinoveriseba.lv
}

\begin{abstract}
The paper's aim is to present how technology companies from Silicon Valley manage diversity after the presidential elections in the US. Also, the paper shows what HR practices on managing diversity are applied across the technology start-ups and what management measure have been taken to tackle diversity in the context of social sustainability. In the paper are used queer theory and the social constructivism as an approach to managing diversity in twenty first century. Furthermore, diversity reports of the technology companies have been analyzed from Silicon Valley. The data sample represents set of ten technology start-ups and different dimensions of diversity have been collected. Subsequently, statistical operationalization has been applied to reveal the links between HR practices and diversity dimensions across the start-ups. The paper argues that majority of the selected technology companies still have diversity deficiencies in terms of diversity in the top management teams. Other paper findings state that the tech companies are making slow steps towards tackling diversity internally. The study provides with applications for tech companies on what HR practices to use and how to sustain amid fierce political decisions and turbulent business environment. Also, the tech sector will benefit from recommendations on handling with diversity. The paper contributes to the queer theory in terms of approaches for managing diversity in the conditions of high innovations and changing governmental policies. The paper possess value to the policy makers and top managers in the Silicon Valley in terms of approaches how to manage diversity.
\end{abstract}

Keywords: Diversity Management, Queer Theory, US Tech Companies.

\section{Introduction}

Scholars and practitioners on diversity and inclusion claim that businesses and firms, which are having particular interest in high competitiveness and sustainability nowadays should invest more in managing diversity and inclusion. There have been calls for more diversity across numerous industries lately: movies, TV, sports, publishing, and more. Discriminatory hiring practices are not a thing of the past, as many of us would like to believe. Although movements like to rectify discriminatory 
behavior and hiring practices, leaders across every industry must still spearhead new solutions to make their fields equal, accessible, and safe.

One industry where the need for diverse representation and hiring is apparent is technology. Technology impacts and is used by us every almost hour of every day. Currently, men hold $76 \%$ of technical jobs, and $95 \%$ of the tech workforce is white (see Figure 1) [2]. There are so many new ideas and developments living in the brains of people who have not been given a chance to act on them, so why let technology be created by limited points of view? We need to add depth to the pool from which tech is born, for everyone's benefit.

Tech companies control almost every facet of daily life, from how we communicate to the ways in which we travel and, even, how we buy our groceries. Their power is seemingly infinite, which is all the reason more why they must make a concerted effort to champion diverse voices from within. Recently Forbes has conducted research on diversity in the US, where the report states that "The people creating this technology have the power to influence how it works, and that's too big a responsibility for any single demographic to have full control. A lack of diverse ideas and representation could lead to further disparities between gender, race, and class." [2].

\subsection{Diversity in the US Tech Companies}

Nowadays many business sectors as the tech business are coming across barriers and hurdles when it comes to managing diversity and inclusion. Moreover, in the modern world of 21 century the companies are employing wide variety of workforce in terms of ethnical background, religion, age and other dimensions of diversity as they have to tackle demanding customers from all over the world. Along with that these organizations should manage strategically diversity throughout all hierarchical levels of the organization and across all branches geographically.

At the same time the tech companies are questioning themselves why there is such a big pressure to manage diversity. In the tech companies the employees supposed to perform quite well in order to survive retention and long-term success, but at the same time these workers would like to make sure that the top management will appreciate and reward their performance. They would like to be treated equally, but at the same time they would like to see teat their employers approach them personally and create very good conditions, so they can perform well. Accordingly, the companies should meet the business requirements and ultimate objectives. It means that tech companies should possess quite broad mindset, which enable them to tackle the diverse workforce regardless differences among the employees. At the same time, the tech companies should apply managerial practices on diversity and inclusion, which will create winwin solutions. Also, diversity management practices are used for increasing employee's well-being and work-life balance, which is vital nowadays in order to avoid burn out. For instance, diversity and inclusion is a one of the main topics from organizational culture, which has been discussed among the tech companies from Silicon Valley.

For example, diversity is a central theme of the culture across Netflix, as well as Google [1]. 
When it comes to employing barriers and hurdles, the tech companies often face difficulties to keep the minority employees, which is quite well demonstrated in many tech companies in Silicon Valley. There the minority workers feel oppressed and under minded, because they are quite different from the majority white workers. They don't feel welcome at the table and they wonder if anyone understands or supports them. For minority employees it could be quite stern to stay in such a kind of job for a long period of time. According to the Queer theory, employee personality is a social construct, which is changing during the life [7]. Therefore, Diversity dimensions should be analyzed through the lenses of social constructivism, where the identity of the employees is similar to fluidity [3].

Table 1. Diversity Management Measures in the US Tech Companies.

\begin{tabular}{lcccccc}
\hline $\begin{array}{l}\text { Company } \\
\text { Name }\end{array}$ & Gender & Age & Disabilities & Minorities & $\begin{array}{c}\text { Sexual } \\
\text { Orient. }\end{array}$ & Religion \\
\hline Google & $\mathrm{X}$ & $\mathrm{X}$ & $\mathrm{X}$ & $\mathrm{X}$ & $\mathrm{X}$ & - \\
Netflix & $\mathrm{X}$ & $\mathrm{X}$ & $\mathrm{X}$ & $\mathrm{X}$ & $\mathrm{X}$ & $\mathrm{X}$ \\
Buffer & $\mathrm{X}$ & $\mathrm{X}$ & $\mathrm{X}$ & $\mathrm{X}$ & - & $\mathrm{X}$ \\
Asana & $\mathrm{X}$ & $\mathrm{X}$ & $\mathrm{X}$ & $\mathrm{X}$ & $\mathrm{X}$ & $\mathrm{X}$ \\
Clef & $\mathrm{X}$ & $\mathrm{X}$ & $\mathrm{X}$ & $\mathrm{X}$ & - & - \\
Facebook & $\mathrm{X}$ & $\mathrm{X}$ & $\mathrm{X}$ & - & - & - \\
Alphabet & $\mathrm{X}$ & $\mathrm{X}$ & $\mathrm{X}$ & - & - & - \\
Apple & $\mathrm{X}$ & $\mathrm{X}$ & $\mathrm{X}$ & $\mathrm{X}$ & $\mathrm{X}$ & $\mathrm{X}$ \\
Biogen & $\mathrm{X}$ & - & - & - & - & - \\
Idec & $\mathrm{X}$ & $\mathrm{X}$ & $\mathrm{X}$ & $\mathrm{X}$ & $\mathrm{X}$ & $\mathrm{X}$ \\
Actavis & & & & &
\end{tabular}

On the surface, quotas sound like a good solution because they increase the number of employees with underrepresented backgrounds in the workplace. But, on a fundamental level, focusing exclusively on hiring and retention numbers is counterproductive. When diversity and inclusion are reduced to data points, it strips the human element from the business. Rather than evangelizing a recruitment approach based on a balanced cultural understanding and the exposure of candidates to an inclusive and egalitarian workplace, execs and HR leaders find themselves glued to spreadsheets and diversity reports [4]. In the paper, we shed a light on the following research questions, which need to be researched:

What Managerial best practices the Tech companies should develop in order to tackle better diversity?

What are the key diversity dimensions, which need to be addressed on National and Federal levels in the US? 


\subsection{Strategies for Increasing Diversity}

While employment opportunities in the technology sector have grown at twice the rate of the national average, high-tech firms have struggled to increase diversity within the workplace. Data compiled from voluntary disclosures to the EEOC reveals large racial and gender disparities within tech workforces as compared to the private sector overall. Recent studies show that improving ethnic and gender diversity within the technology workforce presents an economic opportunity that could result in as much as $\$ 570$ billion in new value for the tech industry, and could add as much as $1.6 \%$ to the national gross domestic product. With a new analysis of challenges to diversity in the tech industry, it is an ideal time for employers to evaluate diversity initiatives currently in use.

Table 2: List of US-based Tech companies having Diversity and Inclusion Measures $(\mathrm{N}=10)$.

\begin{tabular}{lll}
\hline Company Name & $\begin{array}{c}\text { Diversity \& Inclusion } \\
\text { Measures }\end{array}$ & HQ's Location \\
\hline Google & Yes & US \\
Netflix & Yes & US \\
Buffer & Yes & US \\
Asana & Yes & US \\
Clef & Yes & US \\
Facebook & Yes & US \\
Alphabet & Yes & US \\
Apple & Yes & US \\
Nvidia & Yes & US \\
Microsoft & Yes & US \\
\hline
\end{tabular}

\section{Methodology}

In the paper is collected secondary data from the top ten Tech US companies from Silicon Valley with operations in the US and out of US. The US Tech companies are among the top in the Silicon Valley in terms of number of employees, number of branches abroad, profit per one employee and sales growth [5]. The data has been gathered from the companies' websites-section Diversity and Inclusion, their code of conducts and from other secondary based sources as Oracle Database, Fortune 2000 and Thomson Reuters One. In the paper we have gathered the following information: existence of solid and rigorous diversity management strategy and corresponding managerial practices regarding gender, age, sexual orientation, (dis)ability, religion and ethnicity. We have limited the exploration to those diversity dimensions which are covered by the US Federal diversity legislation. In the paper the companies' websites, code of conducts and other secondary based sources have been analyzed in terms of diversity management measures.

According to the Queer Theory, we have withdrawn two hypotheses in the paper as follows [7]: 
Hypothesis 1: Diversity dimensions such as sexual orientation and religion have emerged in recent years among the Tech companies in Silicon Valley in the US.

Hypothesis 2: Sexual orientation and Religion dimensions are still taboo in few Tech companies in Silicon Valley in the US.

\section{Results}

Tech has cultivated a reputation as one of the world's most progressive and forwardthinking industries. The Tech companies still have a long way to go, but hopefully that the industry can provide a model for other industries to follow in the area of diversity and inclusion.

To get there, the Tech companies need to move beyond tokenism and get serious about weaving diversity into the fabric of companies' corporate cultures.

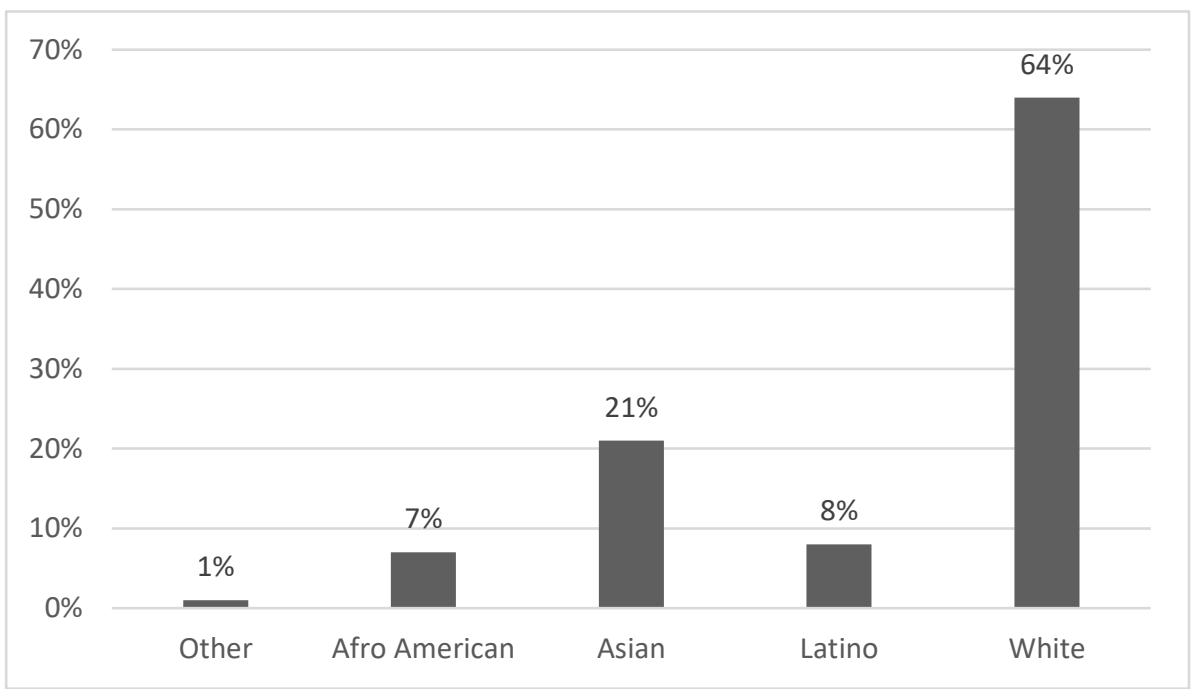

Fig. 1. Diversity in the US Tech Companies by Ethnicity.

Even though diversity dimensions are quantified, they don't create any change. Nowadays, diversity and inclusion are considerably scarce from majority technology companies' missions. It needs some measures to be taken by the top management of these companies. When you manage diversity into organization's mission and core values, it steers the company's vision and actions. As a result, customers and other stakeholders understand that diversity is an essential component of company culture. Furthermore, we can observe that still the tech companies in Silicon Valley are managed mainly by white males and that these companies do not apply management practices to the diversity dimensions as sexual orientation or religion (Figure 1). 


\section{Discussions}

We have analyzed firms' ethical codes and diversity and inclusion reports along with their companies' websites on diversity and inclusion, we are able to withdraw mitigation in the ways how the tech companies are coping with diversity. Vast of the Tech companies from Silicon Valley are putting a lot of efforts and money on Diversity management instruments for improving best practices on diversity and inclusion matters. Along with this there is much of data on how firms supposed to act on diversity characteristics such as sexual orientation, LGBTI rights, etc. This is triggered by the fact that in Silicon Valley there are quite few companies, which develop advanced rules, directives and regulations on coping with diversity and inclusion matters such as age, gender, disability, LGBTI groups in many of the companies there are official regulations, directives or normative documents, which are dealing with diversity dimensions such as sexual orientation due to the fact that there is particular pressure from different authorities and business to be published and announced diversity and inclusion policies [8].

Scholars and practitioners on diversity management have dedicated a lot of time in Western World to show what best practices and approaches have been applied when it comes to organizational culture. In the modern world of globalization and internationalization the countries from Western Europe and North America possess multicultural environment. Similarly, the same phenomenon is valid for the Silicon Valley, where the residents are coming from different ethnical, religious and cultural parts of the Worlds and thus the level of diversity is high [6].

When it comes to nationality, religion, ethnicity, sexual orientation and other diversity characteristically representations. Known nowadays to the practitioners and academicians is the fact that diversity and inclusion are values and aspects pertaining to the Western World but parallelly based on the previous studies and retrospective tracking combined with postcolonial perspectives this phenomenon is emerging [9].

It is proved that there is scarce of data on management practices regarding diversity and inclusion on companies - web-based apps and only several tech companies announce data on trainings and programs for tackling diversity and inclusion in the headquarters.

\section{Conclusion}

Issues regarding diversity and inclusion are not static. Employers may need to periodically revisit diversity initiatives and goals. By utilizing empirically supported activities, however, employers can fine-tune initiatives to progress towards a more diverse workforce.

All in all, companies are on the market in order to serve customers, and they reflect the values of the people they count on to make successful stories. The individualistic approach of firm's business should involve employees from a diverse range of backgrounds - alive, breathing human beings who are more than numbers or ticked boxes. By bringing everyone to the table and working to incorporate diversity and 
inclusion into the fabric of your company culture, you can take an important step toward abandoning tokenism and creating an industry we can all be proud of.

\section{References}

1. Bloomberg website, https://www.bloomberg.com/news/articles/2018-06-26/new-netflixexecutive-to-help-make-staff-as-diverse-as-its-users, last accessed 2018/10/26.

2. Forbes website, https://www.forbes.com/sites/lisawinning/2018/03/13/its-time-toprioritize-diversity-across-tech/\#7cb1 f4d116f8, last accessed 2018/10/28.

3. Kirton, G., Greene, A. M.: The dynamics of managing diversity: A critical approach. 4th edn. Routledge, Taylor \& Francis Group, New York (2015).

4. Mortimore, H.: International Handbook on Diversity Management at Work: Country Perspectives on Diversity and Equal Treatment. Personnel Review. Emerald Group Publishing Limited, Cheltenham (2014).

5. Mupepi, S., Mupepi, M., Modak, A.: Highly Productive 21st Century Workforce: TechSavvy Women in-Charge. In Effective Talent Management Strategies for Organizational Success 218-234 (2017), DOI:10.4018/978-1-5225-1961-4.ch015.

6. Ozturk, M. B, Ahu, T.: Gender Identity Inclusion in the Workplace: Broadening Diversity Management Research and Practice through the Case of Transgender Employees in the UK: The International Journal of Human Resource Management 27(8), 781-802 (2016), DOI:10.1080/09585192.2015.1042902.

7. Parker, M.: Queering Queer: Gender, Work and Organization 23(1), 71-73 (2016), DOI: 10.1111/gwao.12106.

8. Rumens, N., De Souza, E. M., Brewis, J.: Queering queer theory in management and organization studies: notes toward queering heterosexuality. Organization Studies (2018). DOI: $10.1177 / 0170840617748904$.

9. Velinov, E., Malý, M.: Top Management Team Diversity and Company Performance: The moderating effect of Organization Life Cycle. Journal of Eastern European and Central Asian Research (JEECAR) 3(2), 1-11 (2016), DOI: 10.15549/jeecar.v3i2.141. 